\title{
An Unusual Mimicker of Systemic Lupus Erythematosus: A Case Report
}

\author{
Aloice O. Aluoch, Mathew Farbman, and Heather Gladue*
}

Department of Medicine, Division of Rheumatology, Emory University, Atlanta, GA 30322, USA

\begin{abstract}
We present a case of a 47 year-old African American female with 15 pack-years of tobacco use and heavy alcohol use who presented with arthritis and was found to have a positive antinuclear antibodies (ANA), anti double stranded DNA antibodies (anti-dsDNA), and anti-Sjogren's syndrome-related antigen A and antigen B (anti-SSA and anti$\mathrm{SSB}$ ). She was subsequently found to have a lung adenocarcinoma associated with hypertrophic pulmonary osteoarthropathy (HPO). This demonstrates a case of positive antinuclear antibodies and arthritis in a patient with lung adenocarcinoma, which can be falsely diagnosed as systemic lupus erythematosus.
\end{abstract}

Keywords: Adenocarcinoma, antibodies, hypertrophic osteoarthropathy, systemic lupus erythematosus.

\section{INTRODUCTION}

Hypertrophic osteoarthropathy (HOA) is a clinical syndrome characterized by proliferative periostitis of the long bone, arthritis with non-inflammatory synovial fluid mostly affecting the knees and ankles, and digital clubbing [1]. HOA is commonly associated with intra-thoracic malignancies, and primary lung cancer accounts for about $80 \%$ of patients $[2,3]$. A recent large study involving 6151 lung cancer patients found the incidence of HOA to be $1.87 \%$, of which $83 \%$ patients had non-small cell carcinoma [4].

Antinuclear antibodies (ANA) (titer 1:80) frequency is increased by eight-fold in malignancies compared to age matched controls and was reported to be $27 \%$ in lung carcinoma [5]. Although anti-double stranded DNA (antidsDNA) antibodies have a specificity of $97-100 \%$ for systemic lupus erythematosus (SLE) by immunofluorescence assay [6], they have also been reported in malignancies including colorectal adenocarcinoma [7]. Two cases of positive ANA and HOA have been reported in lung bronchial carcinoma and thymic carcinoma [8, 9]. However, this is the first report of positive anti-dsDNA antibodies associated with lung adenocarcinoma in a patient with HOA, a clinical and laboratory presentation which can be misdiagnosed as SLE.

\section{CASE REPORT}

A 47 year-old African American female with a history of 15 pack-years of tobacco use and heavy alcohol use presented with an insidious onset of dry cough and progressive dyspnea over three months associated with swelling of the hands, wrists, elbows, knees, ankles, and feet for six months. She was evaluated for knee pain eight years

*Address correspondence to this author at the Department of Medicine, Division of Rheumatology, Emory University, Atlanta, 1365 Clifton Rd. NE, Building A, 4th Floor, Atlanta, GA 30322, USA; Tel: 404-778-4366; Fax: 404-778-3217; E-mail: Heather.gladue@emory.edu earlier and $\mathrm{x}$-ray showed bilateral osteonecrosis which was attributed to heavy alcohol use. ANA was positive but she denied alopecia, malar rash, dry eyes, dry mouth, parotid gland enlargement, Raynaud's phenomenon, photosensitive rashes, pleurisy, oral/nasal ulcers, and dark urine over the past eight years. She denied hemoptysis but reported a 10 pound weight loss over three months associated with fevers, dyspnea, chills, nausea, vomiting and inability to keep food down for two weeks.

On physical examination, the patient was thin, but with clubbing of all her fingers but not toes (Fig. 1). She was

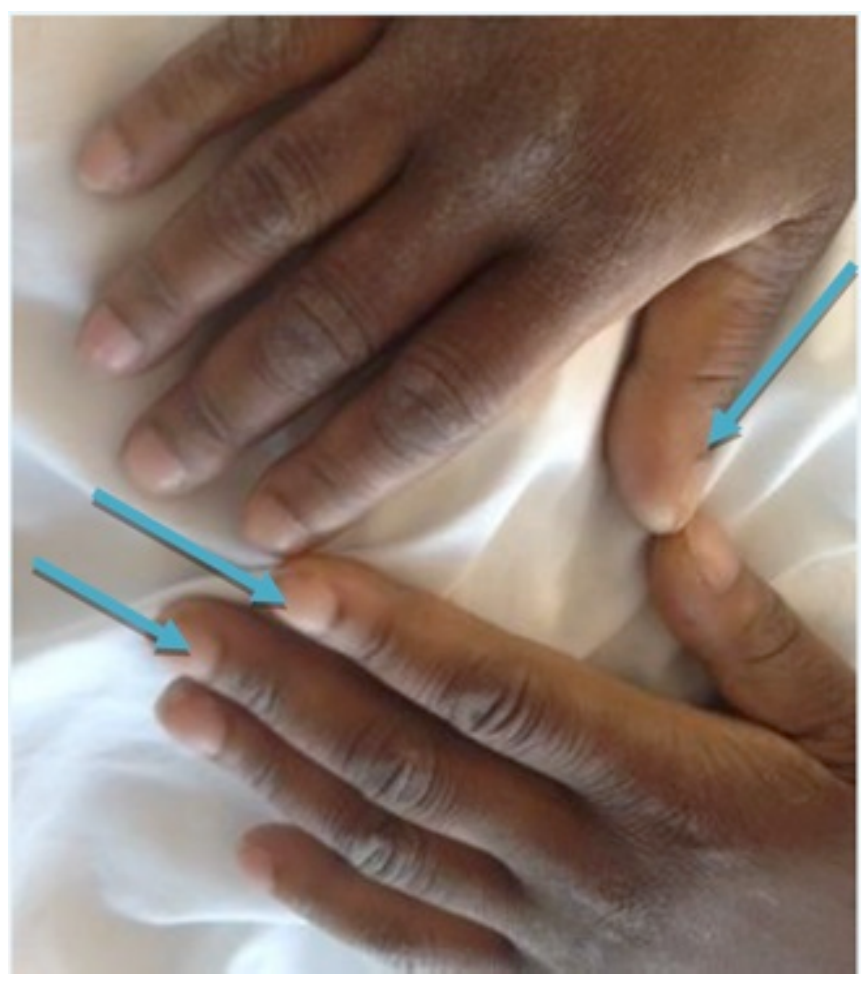

Fig. (1). Digital clubbing in hands (blue arrows). 
afebrile and did not have a malar rash, alopecia, or oral/nasal ulcers. On musculoskeletal examination, there were moderate knee effusions and mild warmth without overlying erythema. The proximal tibia and distal femur were exquisitely tender to palpation as was palpation of the distal tibia bilaterally. There were crackles in the left upper hemithorax. Her blood pressure was $131 / 85 \mathrm{mmHg}$, pulse was 83 , and there were no heart murmurs or pericardial rubs. She did not have any neurological deficits.

Laboratory studies are summarized on Table 1. The significant lab findings at admission were: hemoglobin 9.7 $\mathrm{g} / \mathrm{dl}$, hematocrit $29.6 \%$, platelets $830,000 / \mathrm{ml}$, erythrocyte sedimentation rate $111 \mathrm{~mm} /$ first hour, C-reactive protein

Table 1. Selected laboratory results.

\begin{tabular}{|c|c|c|}
\hline Laboratory Test & Results & Reference Range \\
\hline Sodium-Serum & 136 & $132-144 \mathrm{mEq} / \mathrm{L}$ \\
\hline Potassium-Serum & 3.8 & $3.4-5.1 \mathrm{mEq} / \mathrm{L}$ \\
\hline Chloride-Serum & 94 & $101-111 \mathrm{mEq} / \mathrm{L}$ \\
\hline $\mathrm{CO}_{2}$ Content-Serum & 33 & $22-32 \mathrm{mEq} / \mathrm{L}$ \\
\hline Glucose & 126 & $70-125 \mathrm{mg} / \mathrm{dL}$ \\
\hline Urea Nitrogen-Serum & 5 & $8-22 \mathrm{mg} / \mathrm{dL}$ \\
\hline Creatinine-Serum & 0.6 & $0.4-1.0 \mathrm{mg} / \mathrm{dL}$ \\
\hline Glomerular Filtration Rate Calc & $>60$ & $>60 \mathrm{~mL} / \mathrm{min} / 1.73 \mathrm{~m}^{\wedge} 2$ \\
\hline Osmo, Calculated & 271 & $275-300 \mathrm{mOsm} / \mathrm{L}$ \\
\hline Protein, Total-Serum & 6.4 & $6.0-8.3 \mathrm{~g} / \mathrm{dL}$ \\
\hline Albumin & 3.2 & $3.5-5.0 \mathrm{~g} / \mathrm{dL}$ \\
\hline AST (SGOT) & 12 & $10-42 \mathrm{U} / \mathrm{L}$ \\
\hline ALT (SGPT) & 7 & $14-54 \mathrm{U} / \mathrm{L}$ \\
\hline WBC Count-Blood & 6.9 & $4.0-10.8 \mathrm{~K} / \mathrm{mcL}$ \\
\hline RBC Count-Blood & 3.42 & $3.90-5.20 \mathrm{M} / \mathrm{mcL}$ \\
\hline Hemoglobin-Blood & 9.8 & $11.5-15.5 \mathrm{~g} / \mathrm{dL}$ \\
\hline Hematocrit-Blood & 30.3 & $35.0-45.0 \%$ \\
\hline $\mathrm{RBC} \mathrm{MCV}$ & 89 & $80-97 \mathrm{fL}$ \\
\hline $\mathrm{RBC} \mathrm{MCHC}$ & 32.5 & $32.0-36.0 \mathrm{~g} / \mathrm{dL}$ \\
\hline RBC RDW & 16.2 & $11.5-14.5 \%$ \\
\hline Platelet Count-Blood & 922 & $140-440 \mathrm{~K} / \mathrm{mcL}$ \\
\hline$\%$ Neutrophils-Blood & 73 & $25-62 \%$ \\
\hline$\%$ Monocytes-Blood & 8 & $2-11 \%$ \\
\hline \% Lymphoctyes-Blood & 17 & $20-53 \%$ \\
\hline Complement C3 & 169 & $87-200 \mathrm{mg} / \mathrm{dl}$ \\
\hline Complement C4 & 59 & $19-52 \mathrm{mg} / \mathrm{dL}$ \\
\hline Anti-dsDNA & 172 & 0-120 AU/mL \\
\hline SSA & 204 & $0-120 \mathrm{AU} / \mathrm{mL}$ \\
\hline SSB & 123 & $0-120 \mathrm{AU} / \mathrm{mL}$ \\
\hline Smith & 14 & $0-120 \mathrm{AU} / \mathrm{mL}$ \\
\hline RNP & 16 & $0-120 \mathrm{AU} / \mathrm{mL}$ \\
\hline WBC Count-Synovial Fluid & $232(\mathrm{H})$ & $0-10 / \mathrm{mcL}$ \\
\hline RBC Count-Synovial Fluid & 686 & - \\
\hline
\end{tabular}

$14.82 \mathrm{mg} / \mathrm{dl}$, ANA positive by ELISA (Bio-Rad EIA kit), an extended ANA profile was positive for anti-dsDNA 170 IU/ML (Bio-rad EIA dilution 1:100), anti-SSA 204 AU/ML (Bio-rad EIA kit), and anti-SSB 123 (Bio-rad EIA kit). Complement C3 was 169 and complement C4 was 59. Urinalysis was negative for protein but positive for leukocyte esterase with 11-25 WBCs and 2-5 RBCs. Knee effusion was aspirated and the synovial fluid cell count was 232 white blood cells/microliter.

Chest X-rays showed left upper lobe opacity. Computed tomograpy of the chest showed a superior left upper lobe mass measuring 4.3 by $3.8 \mathrm{~cm}$ (Fig. 2). X-ray of the right leg showed cortical bone hypertrophy (periostitis) (Fig. 3). Biopsy of the left upper lobe mass led to the diagnosis of lung adenocarcinoma. Joint pain and swelling resolved by her follow up one month later after chemo-radiotherapy.

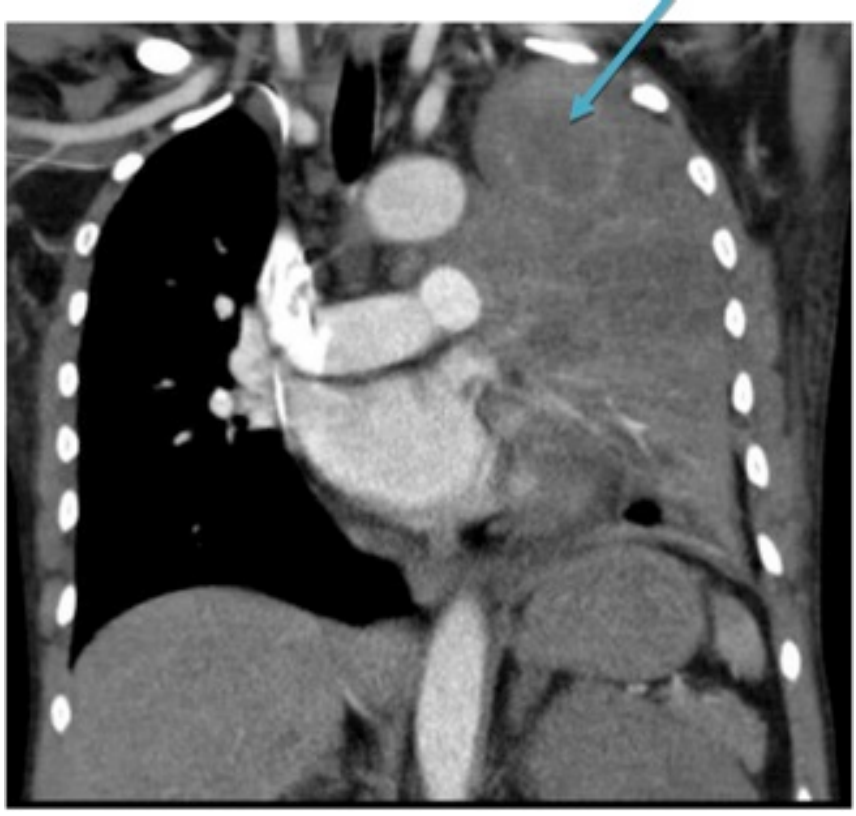

Fig. (2). Chest computed tomography shows left upper lobe mass (blue arrow).

\section{DISCUSSION}

Positive ANA has been detected in several malignancies and although anti-dsDNA antibodies are specific for the diagnosis of SLE in the correct clinical setting, there is growing evidence for its presence in several malignancies $[7,10]$. The presence of autoantibodies in malignancy suggests a possible antibody dependent mechanism in eradicating the malignant cells as patients diagnosed with stage III non-small cell lung cancer (NSCLC) with positive ANAs had an improved survival compared to those who did not [11].

This case of HOA and lung adenocarcinoma with positive auto antiantibodies (ANA, anti-dsDNA, anti-SSA, and anti-SSB) can be misdiagnosed as SLE, especially in the presence of a joint effusion, chest pain, and dyspnea. Although the differential diagnoses for SLE is large, the clinician should consider HOA with associated malignancies when a patient presents with digital clubbing and noninflammatory arthritis. 


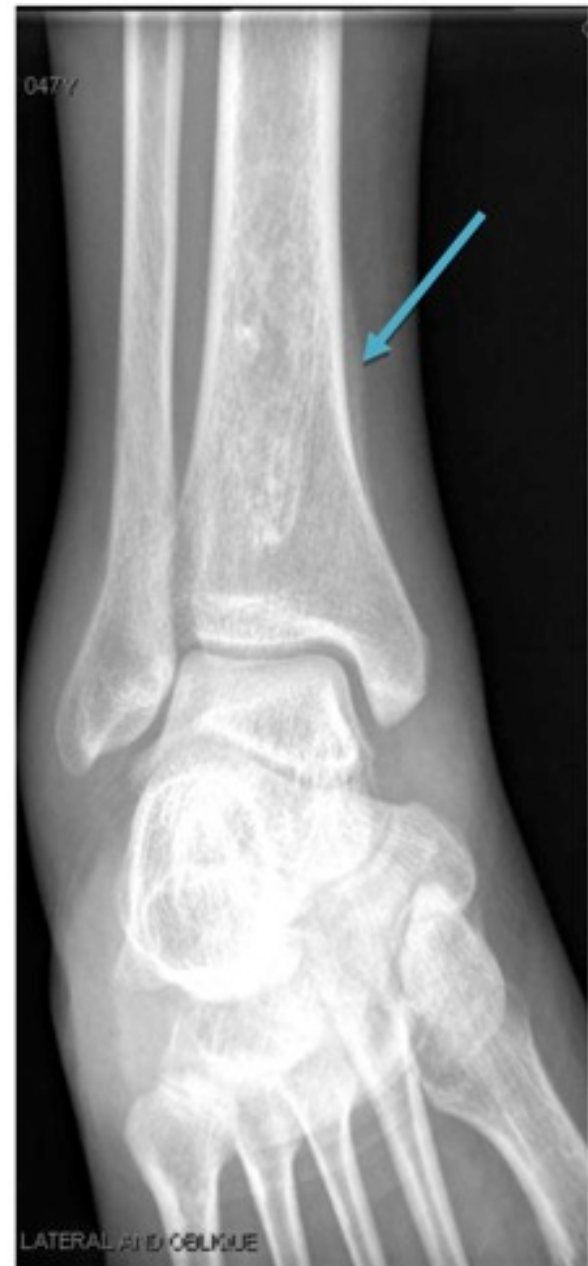

Fig. (3). Right medial tibia periostitis (blue arrow).

Our patient was also a smoker and tobacco use has been associated with positive anti-dsDNA antibodies and increased disease activity in SLE [12]. In a large crosssectional study of healthy individuals, anti-dsDNA antibodies were not detected and ANA positivity could not be linked to either smoking or alcohol intake [13]. The increased cell death and deficient elimination of cellular debris may expose intracellular antigens to immune system and lead to autoantibody formation. In addition, the presence of autoantibodies in malignancy may represent an immune response important in eradicating the malignant cells [14].

In the context of extended history of tobacco use, positive antinuclear antibodies with positive anti-dsDNA antibodies, a thorough evaluation by a rheumatologist is essential for making proper diagnosis. We can conclude that patients who do not meet a diagnosis of an autoimmune connective tissue disease should be followed regularly and evaluated for alternative diagnoses including malignancy. In addition, age appropriate malignancy screening and low-dose computed tomography of the chest should be strongly considered [15].

\section{CONFLICT OF INTEREST}

The authors confirm that this article content has no conflict of interest.

\section{ACKNOWLEDGEMENTS}

Declared none.

\section{REFERENCES}

[1] Walker E, Logie CI, Murphy MD. Hypertrophic osteoarthropathy In: Pope TL, Ed. Musculoskeletal imaging. $2^{\text {nd }}$ ed. Philadelphia: Elsevier Saunders 2015.

[2] Benedek TG. Paraneoplastic digital clubbing and hypertrophic osteoarthropathy. Clin Dermatol 1993; 11(1): 53-9.

[3] Hammarsten JF, O'Leary J. The features and significance of hypertrophic osteoarthropathy. AMA Arch Intern Med 1957; 99(3): $431-41$

[4] Qian X, Qin J. Hypertrophic pulmonary osteoarthropathy with primary lung cancer. Oncol Lett 2014; 7(6): 2079-82.

[5] Solans-Laque R, Perez-Bocanegra C, Salud-Salvia A, et al. Clinical significance of antinuclear antibodies in malignant diseases: association with rheumatic and connective tissue paraneoplastic syndromes. Lupus 2004; 13(3): 159-64.

[6] Wichainun R, Kasitanon N, Wangkaew S, Hongsongkiat S, Sukitawut W, Louthrenoo W. Sensitivity and specificity of ANA and anti-dsDNA in the diagnosis of systemic lupus erythematosus: a comparison using control sera obtained from healthy individuals and patients with multiple medical problems. Asian Pac J Allergy Immunol 2013; 31(4): 292-8.

[7] Syrigos KN, Charalambopoulos A, Pliarchopoulou K Varsamidakis N, Machairas A, Mandrekas D. The prognostic significance of autoantibodies against dsDNA in patients with colorectal adenocarcinoma. Anticancer Res 2000; 20(6B): 4351-3.

[8] Cruz C, Rocha M, Andrade D, et al. Hypertrophic pulmonary osteoarthropathy with positive antinuclear antibodies: case report. Case Rep Oncol 2012; 5(2): 308-12.

[9] Di Cataldo A, Villari L, Milone P, et al. Thymic carcinoma, systemic lupus erythematosus, and hypertrophic pulmonary osteoarthropathy in an 11-year-old boy: a novel association. Pediatr Hematol Oncol 2000; 17(8): 701-6.

[10] Shoenfeld Y, Ben-Yehuda O, Napartstek Y, et al. The detection of a common idiotype of anti-DNA antibodies in the sera of patients with monoclonal gammopathies. J Clin Immunol 1986; 6(3): 194 204.

[11] Blaes F, Klotz M, Huwer H, et al. Antineural and antinuclear autoantibodies are of prognostic relevance in non-small cell lung cancer. Ann Thorac Surg 2000; 69(1): 254-8.

[12] Arnson Y, Shoenfeld Y, Amital H. Effects of tobacco smoke on immunity, inflammation and autoimmunity. J Autoimmun 2010; 34(3): J258-65.

[13] Satoh M, Chan EK, Ho LA, et al. Prevalence and sociodemographic correlates of antinuclear antibodies in the United States. Arthritis Rheum 2012; 64(7): 2319-27.

[14] Torchilin VP, Iakoubov LZ, Estrov Z. Antinuclear autoantibodies as potential antineoplastic agents. Trends Immunol 2001; 22(8): 424-7.

[15] Aberle DR, Adams AM, Berg CD, et al. Reduced lung-cancer mortality with low-dose computed tomographic screening. N Engl J Med 2011; 365(5): 395-409.

This is an open access article licensed under the terms of the Creative Commons Attribution Non-Commercial License (http://creativecommons.org/licenses/by-nc/ 3.0/) which permits unrestricted, non-commercial use, distribution and reproduction in any medium, provided the work is properly cited. 